\title{
'Fat but powerful' paradox: association of muscle power and adiposity markers with all-cause mortality in older adults from the EXERNET multicentre study
}

\author{
Julian Alcazar (D) , 1,2 David Navarrete-Villanueva, ${ }^{3,4}$ Asier Mañas, 1,2 \\ Alba Gómez-Cabello, 3,5,6 Raquel Pedrero-Chamizo, ${ }^{7}$ Luis M Alegre, ${ }^{1,2}$ Gerardo Villa, ${ }^{8}$ \\ Narcís Gusi, ${ }^{2,9,10}$ Marcela González-Gross, ${ }^{6,7}$ Jose Antonio Casajús (D) , 3,4,6 \\ German Vicente-Rodriguez, ${ }^{3,6,11}$ Ignacio Ara (D) ${ }^{1,2}$
}

For numbered affiliations see end of article.

\section{Correspondence to}

Dr Ignacio Ara, Universidad de Castilla-La Mancha - Campus de Toledo, Toledo 13001, CastillaLa Mancha, Spain; ignacio.ara@uclm.es

Accepted 10 March 2021
Check for updates

(c) Author(s) (or their employer(s)) 2021. No commercial re-use. See rights and permissions. Published by BMJ.

To cite: Alcazar J, NavarreteVillanueva D, Mañas A, et al. Br J Sports Med Epub ahead of print: [please include Day Month Year]. doi:10.1136/ bisports-2020-103720

\section{ABSTRACT}

Objectives To assess the influence of muscle power and adiposity on all-cause mortality risk and to evaluate the 'fat but powerful' ( $F+P$ ) (or 'fat but fit') paradox in older adults.

Methods A total of 2563 older adults (65-91 years old) from the EXERNET multicentre study were included. Adiposity (body mass index (BMI), waist circumference, body fat percentage (BF\%) and fat index), allometric and relative power (sit-to-stand muscle power test) and various covariates (age, sex, hypertension, smoking status and walking and sitting times per day) were registered at baseline. All-cause mortality was recorded during a median follow-up of 8.9 years. Participants were classified into four groups: lean and powerful $(L+P), F+P$, lean but weak and fat and weak $(F+W)$. Cox proportional hazard regression models and adjusted HRs were calculated.

Results According to BMl and waist circumference, all-cause mortality risk was reduced in the $\mathrm{F}+\mathrm{P}$ ( $H R=0.55$ and $0.63, p=0.044$ and 0.049 , respectively) and $L+P(H R=0.57$ and $0.58, p=0.043$ and 0.025 , respectively) groups. According to $\mathrm{BF} \%$, all-cause mortality decreased in the $\mathrm{L}+\mathrm{P}$ group $(\mathrm{HR}=0.53$; $p=0.021$ ), and a trend for a reduction was reported in the $F+P$ group ( $H R=0.57 ; p=0.060)$. According to fat index, a survival benefit was only noted in the $\mathrm{L}+\mathrm{P}$ group $(H R=0.50 ; p=0.049)$. Higher levels of relative power reduced all-cause mortality risk among older people ( $H R=0.63$ and $0.53, p=0.006$ and 0.011 , respectively). Conclusion Powerful older people exhibited a reduced 9-year all-cause mortality regardless of BMI, waist circumference and $\mathrm{BF} \%$. Obesity according to fat index blunted the survival benefits of being powerful.

\section{INTRODUCTION}

Physical fitness has been identified as one of the most important predictors of all-cause mortality among adults. Specifically, low cardiorespiratory fitness has been shown to be responsible for a greater number of deaths than other risk factors such as hypertension, smoking or metabolic disease. ${ }^{12}$ The relevance of achieving an adequate physical fitness status is such that people with obesity or metabolic disease who present adequate cardiorespiratory fitness exhibit a diminished mortality risk when compared with people without obesity or metabolic disease but presenting low cardiorespiratory fitness. ${ }^{3}$ This has been described as the 'fat but fit' paradox. ${ }^{4}$

The 'fat but fit' paradox has also been confirmed in older adults. Sui et $a l^{5}$ demonstrated that maintaining an adequate cardiorespiratory fitness at older age decreases all-cause mortality risk independently of overall or abdominal adiposity. However, the assessment of cardiorespiratory fitness can demand considerable time and resources from the practitioners and requires an effort until exhaustion from the older participants, which may limit its routine application in the clinical setting. Among the other components of physical fitness, muscle power (ie, product of force and velocity) has been found to be more strongly related with older adults' functional status than cardiorespiratory capacity. ${ }^{6}$ Muscle power has also been reported to predict all-cause mortality among men, independently of physical activity, muscle mass and strength. ${ }^{7}$ Fortunately, muscle power can be assessed using a feasible procedure that only requires a chair and a stopwatch and a few seconds to be conducted: the sit-to-stand (STS) muscle power test. ${ }^{89}$ Nevertheless, no studies have previously assessed the 'fat but fit' paradox while considering muscle power as the physical fitness component, which might be of special relevance in older populations. Hence, the main goals of the present investigation were twofold: (1) to evaluate and compare all-cause mortality risk in a representative sample of non-institutionalised Spanish older adults presenting different combinations of adiposity and muscle power and (2) to determine whether the 'fat but fit' paradox occurs when muscle power is regarded.

\section{METHODS}

\section{Study design}

This is a prospective study conducted in the participants of the EXERNET multicentre study (for further details, see Gomez-Cabello et al and Pedrero-Chamizo et $a l^{10}{ }^{11}$ ). This study includes a representative sample of noninstitutionalised older adults ( $\geq 65$ years old) living in Spain. Data were collected from June 2008 to November 2009 by means of personal interviews and physical examination (body composition and physical fitness). All the participants gave their written informed consent. The study was approved by the Clinical Research Ethics Committee of Aragón (18/2008) 
Table 1 Baseline characteristics of the study participants

\begin{tabular}{|c|c|c|}
\hline & Men $(n=602)$ & Women $(n=1961)$ \\
\hline & Mean \pm SD & Mean \pm SD \\
\hline Age (years) & $72.1 \pm 5.4$ & $72.0 \pm 5.2$ \\
\hline Body mass $(\mathrm{kg})$ & $77.6 \pm 11.0$ & $68.9 \pm 10.7$ \\
\hline Height (m) & $1.65 \pm 0.07$ & $1.53 \pm 0.06$ \\
\hline BMI $\left(\mathrm{kg} \cdot \mathrm{m}^{-2}\right)$ & $28.3 \pm 3.5$ & $29.5 \pm 4.3$ \\
\hline Waist circumference $(\mathrm{cm})$ & $99.2 \pm 10.0$ & $93.0 \pm 12.3$ \\
\hline Body fat (\%) & $29.1 \pm 5.1$ & $39.7 \pm 5.2$ \\
\hline Fat index $\left(\mathrm{kg} \cdot \mathrm{m}^{-2}\right)$ & $8.3 \pm 2.2$ & $11.9 \pm 3.1$ \\
\hline STS performance (reps) & $15.0 \pm 3.6$ & $14.1 \pm 3.3$ \\
\hline Allometric power $\left(\mathrm{W} \cdot \mathrm{m}^{-2}\right)$ & $99.8 \pm 26.0$ & $80.8 \pm 20.4$ \\
\hline Relative power $\left(\mathrm{W} \cdot \mathrm{kg}^{-1}\right)$ & $3.54 \pm 0.83$ & $2.76 \pm 0.67$ \\
\hline Hypertension (yes, $\mathrm{n}(\%)$ ) & $317(52.6)$ & $984(50.2)$ \\
\hline Smoking (yes, n(\%)) & $54(9.0)$ & $33(1.7)$ \\
\hline Walking $<1$ hour $\cdot$ day $^{-1}$ (yes, $\left.n(\%)\right)$ & $170(28.2)$ & $696(35.5)$ \\
\hline Sitting $\geq 5$ hour $\cdot$ day $^{-1}$ (yes, $n(\%)$ ) & $110(18.3)$ & $284(14.5)$ \\
\hline
\end{tabular}

BMI, body mass index; STS, sit-to-stand.

and the Ethical Committee of the University Hospital Fundación Alcorcón (50/2016), and the procedures were performed in accordance with the Helsinki Declaration.

\section{Participants}

A total of 2563 older adults (602 older men and 1961 older women; all Caucasian) were included in this study. Inclusion criteria were age $\geq 65$ years and independent living. Older people with dementia, cancer or terminal illness were excluded. Baseline information of the study participants is shown in table 1.

\section{Anthropometrics and body composition}

Subjects remained in the standing position without shoes and shocks while using light clothing. Any metal object was removed. Height and body mass were assessed with a portable stadiometer and scale device (SECA 225, SECA, Germany), and body mass index (BMI; $\mathrm{kg} \cdot \mathrm{m}^{-2}$ ) was calculated as the ratio between body mass and height squared. Waist circumference $(\mathrm{cm})$ was measured at the narrowest point between the lower border of the last rib and the iliac crest with an inelastic measuring tape (Rosscraft Innovations, Canada). Whole body fat was estimated using a bioelectrical impedance analyzer (Tanita BC-418 MA, Tanita, Japan). Body fat percentage (\%) was calculated as the ratio between body fat and body mass. Fat index $\left(\mathrm{kg} / \mathrm{m}^{2}\right)$ was calculated as the ratio between body fat and height squared. Then, obesity was identified separately in men and women for the different adiposity indexes: $\mathrm{BMI} \geq 30 \mathrm{~kg} / \mathrm{m}^{2}$ in both men and women $^{12}$; waist circumference $\geq 101 \mathrm{~cm}$ in men and $\geq 88 \mathrm{~cm}$ in women ${ }^{13}$; body fat percentage $\geq 31 \%$ in men and $\geq 43 \%$ in women $^{14}$ and fat index $\geq 9.05 \mathrm{~kg} / \mathrm{m}^{2}$ in men and $\geq 13.06 \mathrm{~kg} / \mathrm{m}^{2}$ in women (highest sex-specific quintiles).

\section{Muscle power}

Muscle power was evaluated with the 30 s STS muscle power test. ${ }^{9}$ This test consists of performing as many STS repetitions as possible within $30 \mathrm{~s}$ on a standardised armless chair. Then, muscle power is calculated by means of a validated equation that considers the participant's body mass and height, chair height $(0.43 \mathrm{~m})$ and $30 \mathrm{~s}$ STS performance. Strong verbal encouragement was given to all the participants throughout the test. Absolute muscle power values were normalised to height squared (i.e. allometric musle power) due to absolute muscle power is positively associated with height $(\mathrm{r}=0.48$ in men and 0.47 in women). ${ }^{15}$ Low allometric power was identified in men with values $<75.4 \mathrm{~W} / \mathrm{m}^{2}$ and in women with values $<61.5 \mathrm{~W} / \mathrm{m}^{2}$ (lowest sex-specific quintile), while values equal to or greater than these cut-off points were considered normal. In addition, relative muscle power $\left(\mathrm{W} / \mathrm{kg}^{1}\right)$ is a measure of muscle power that integrates information on physical fitness and adiposity levels since it can be calculated as allometric muscle power normalised to BMI. Of note, relative muscle power can also be obtained from the ratio between absolute muscle power and body mass. Low relative power was defined as showing values $<2.6 \mathrm{~W} / \mathrm{kg}^{1}$ in men and $<2.1 \mathrm{~W} / \mathrm{kg}^{1}$ in women (lowest sex-specific quintile), otherwise relative muscle power was considered normal. In addition, high relative power was identified in men with values $\geq 4.0 \mathrm{~W} / \mathrm{kg}^{1}$ and in women with values $\geq 3.2 \mathrm{~W} / \mathrm{kg}^{1}$ (highest sexspecific quintile).

\section{Covariates}

Based on the evidence regarding mortality attributable to selected major risks, hypertension, smoking status, and physical activity and inactivity were registered. ${ }^{16}$ Resting systolic blood pressure was assessed with the participants in the sitting position and after $10 \mathrm{~min}$ of rest. The average of two measurements separated by 2 min was obtained for further analysis. Hypertension was considered in participants with systolic blood pressure $\geq 140 \mathrm{~mm} \mathrm{Hg}$. Smoking status, walking time and sedentary time were self-reported by the participants during the personal interviews through a validated questionnaire. ${ }^{17}$ Subjects were categorised into two groups of smoking status (yes and no), two groups of physical activity (walking $\geq 1$ hour and $<1$ hour/day; based on the highest quintile) and two groups of sedentary time (sitting $\geq 5$ hour and $<5$ hour/day, based on the highest quintile).

\section{Survival data}

All-cause mortality was collected in the study participants consulting the Spanish National Death Index during a median follow-up of 8.9 years (IQR $=8.5-9.1$ years) that elapsed from the date of interview to the date of death or censoring (31 March 2018).

\section{Statistical analyses}

Data were presented as mean \pm SD for continuous variables and as frequency and percentage for categorical variables. All continuous variables presented skewness values ranging between -0.46 and 0.62 and kurtosis values ranging between -0.18 and 1.11 , and so they were treated as normally distributed variables. Differences between deceased and surviving participants were assessed separately in men and women using unpaired t-tests for continuous variables (homogeneity of variances was assessed by Levene's test) and $\chi^{2}$ tests for categorical variables (Fisher's exact test was applied when expected counts were $<5$ ). To assess the 'fat but powerful' $(\mathrm{F}+\mathrm{P})$ paradox, four mutually exclusive groups were created for each adiposity variable: (1) lean and powerful $(\mathrm{L}+\mathrm{P})$ (nonobese people with normal allometric power), (2)F $+\mathrm{P}$ (obese people with normal allometric power), (3) lean but weak $(\mathrm{L}+\mathrm{W})$ (nonobese people with low allometric power) and (4) fat and weak $(\mathrm{F}+\mathrm{W})$ (obese people with low allometric power). Finally, HRs and 95\% CIs of allcause mortality for each corresponding group of adiposity and allometric power (reference: $\mathrm{F}+\mathrm{W}$ group) were calculated using Cox proportional hazards regression models, with time-on-study since data collection (months) as the time-scale, adjusted for age, sex (reference: men), hypertension, smoking status, walking 


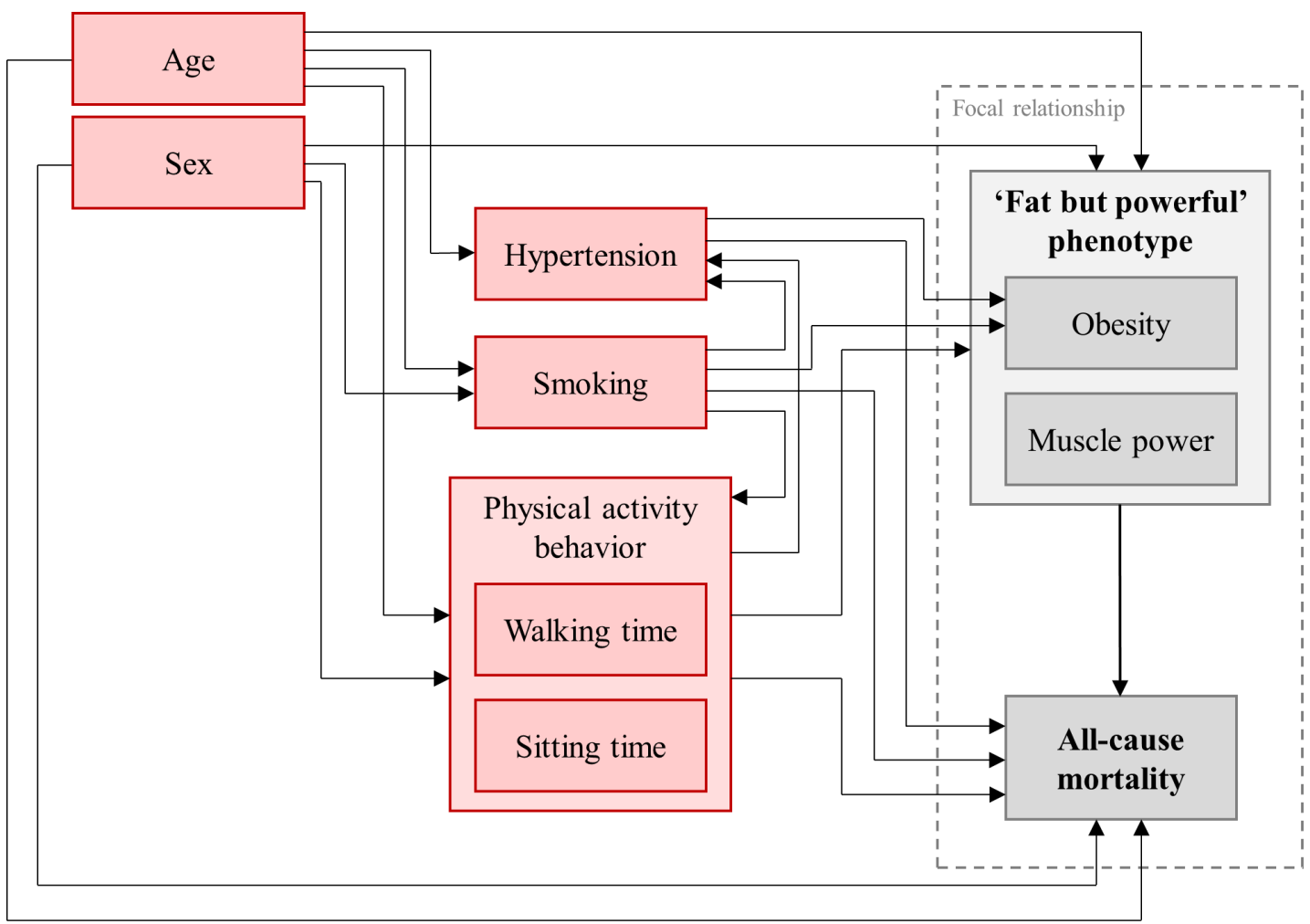

Figure 1 Directed acyclic graph showing the relationship between the exposure ('Fat but powerful' phenotype) and outcome (all-cause mortality) variables (grey nodes), and the potential influence of several confounders (red nodes).

$<1$ hour/day and sitting $\geq 5$ hour/day (all reference: no)). A directed acyclic graph is presented in figure 1 to illustrate the relation between the group of confounders and the exposure and outcome variables. Deaths within the first 2 years were excluded to minimise bias from reverse causation. ${ }^{18}$ The proportional hazard assumption was evaluated and confirmed by examination of the Kaplan-Meier curves showing survival probability over time. The linearity assumption was evaluated and confirmed by plotting Martingale residuals (y-axis) against age (x-axis). In addition, HR and $95 \% \mathrm{CI}$ of all-cause mortality for each group of relative muscle power, as well as for relative muscle power introduced as a continuous variable, were obtained adjusting for the same covariates. The statistical power $(1-\beta)$ of each comparison between the reference group and each of the other groups was analysed according to the procedures reported elsewhere for survival analyses. ${ }^{19}$ The parameters considered were $\alpha$ (two-tailed) $=0.05 ; \mathrm{q}_{1}$ (proportion of subjects in the reference group); $\mathrm{q}_{0}$ (proportion of subjects in the other group); relative hazard (between the reference group and each of the other groups) and the total number of events recorded in the groups being compared. ${ }^{19}$ Statistical power values ranged between 0.87 and 0.97 regardless of the adiposity marker used to assess the ' $\mathrm{F}+\mathrm{P}$ ' phenotype, except for the comparisons between the $\mathrm{F}+\mathrm{W}$ (reference) and $\mathrm{L}+\mathrm{W}$ group, that showed statistical power values ranging from 0.18 to 0.62 . All statistical analyses were performed using SPSS V.20 (SPSS, USA) and the level of significance was set at $\alpha=0.05$.

\section{RESULTS}

A total of 241 older subjects (56 older men and 185 older women) were excluded due to loss to follow-up. The excluded participants were younger (70.8 vs 72.2 years old; $p<0.001)$, had greater waist circumference ( 96.1 vs $94.3 \mathrm{~cm} ; \mathrm{p}=0.003)$ and allometric $\left(89.0\right.$ vs $\left.84.2 \mathrm{~W} / \mathrm{m}^{2} ; \mathrm{p}<0.001\right)$ and relative $(3.0$ vs $\left.2.9 \mathrm{~W} / \mathrm{kg}^{1} ; \mathrm{p}=0.005\right)$ muscle power levels and were less likely to have hypertension $(41.4$ vs $52.0 \% ; \mathrm{p}<0.001)$ compared with the participants that completed the follow-up period (median=8.9 years; IQR=8.5-9.1 years). No differences were reported regarding sex, physical performance, smoking, physical activity behaviour and the other measures of body composition (all $\mathrm{p}>0.05$ ).

\section{Comparison between deceased and surviving older people}

Of the participants that completed the 9-year follow-up, a total of $215(9.3 \%)$ participants died (86 (15.8\%) men and $129(7.3 \%)$ women) and 2107 (90.7\%) participants were censored (460 (84.2\%) men and 1647 (92.7\%) women) (ie, did not present any event). Deceased men were older (mean difference $(95 \% \mathrm{CI}$ ) 3.8 (2.4 to 5.1) years old; $\mathrm{p}<0.001$ ), presented lower allometric and relative muscle power values at baseline $(-8.8(-14.7$ to -3.0$) \mathrm{W} / \mathrm{m}^{2}, \mathrm{p}=0.003$ and $-0.26(-0.45$ to -0.08$) \mathrm{W} / \mathrm{kg}^{1}$, $\mathrm{p}=0.006$, respectively) and were less likely to have hypertension $(p=0.004)$ and more likely to be smokers $(p=0.030)$ when compared with surviving men (table 2). No differences were noted between deceased and surviving men regarding BMI, waist circumference, body fat percentage, fat index, STS performance and walking and sitting times (all $\mathrm{p}>0.05$ ). Among women, those who died were older (4.5 (3.6 to 5.4) years old; $\mathrm{p}<0.001$ ), exhibited lower values of STS performance $(-1.0(-1.7$ to -0.4$)$ reps; $\mathrm{p}=0.003)$, allometric power $\left(-8.1(-11.8\right.$ to -4.5$) \mathrm{W} / \mathrm{m}^{2}$; $\mathrm{p}<0.001)$ and relative power $\left(-0.28(-0.41\right.$ to -0.14$) \mathrm{W} / \mathrm{kg}^{1}$; $\mathrm{p}<0.001)$ and were more likely to have hypertension $(\mathrm{p}=0.026)$ than the surviving women (table 2). No differences were found between deceased and surviving women in terms of BMI, waist circumference, body fat percentage, fat index, walking and sitting times and smoking status (all $\mathrm{p}>0.05$ ). 


\section{Original research}

Table 2 Comparison between deceased and surviving older men and women

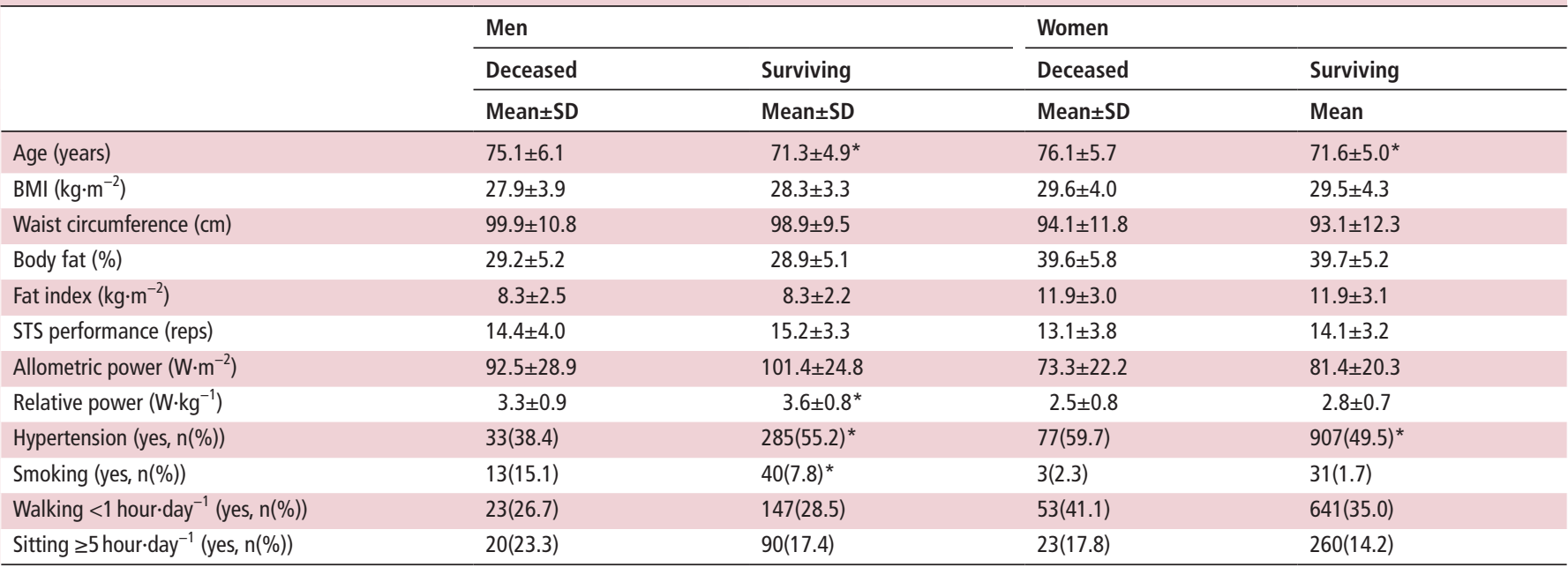

*Statistically significant differences between deceased and surviving participants $(p<0.01)$.

BMI, body mass index; STS, sit-to-stand.

Comparisons among groups of power and adiposity regarding all-cause mortality

Survival plots showing the cumulative probability of survival among the different groups of allometric muscle power and adiposity are displayed in figure 2 .

Among the groups of allometric muscle power and BMI, HRs of all-cause mortality were significantly reduced in the F+P (HR
(95\% CI) 0.55 (0.31 to 0.98); p=0.044) and L+P (HR $(95 \% \mathrm{CI})$ 0.57 (0.33 to 0.98$) ; \mathrm{p}=0.043)$ groups when compared with the $\mathrm{F}+\mathrm{W}$ group. No significant differences existed between the $\mathrm{L}+\mathrm{W}$ participants $(\mathrm{HR}(95 \% \mathrm{CI}) 0.80(0.45$ to 1.44$) ; \mathrm{p}=0.462)$ and the reference group (figure $3 \mathrm{~A}$ ).

Similarly, when allometric power and waist circumference were regarded, all-cause mortality risk was significantly reduced

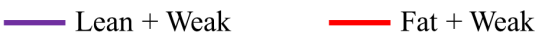

\section{Allometric power and waist circumference}

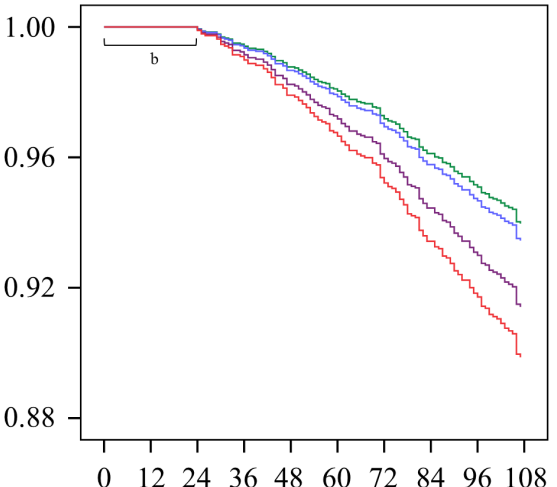

Allometric power and fat index

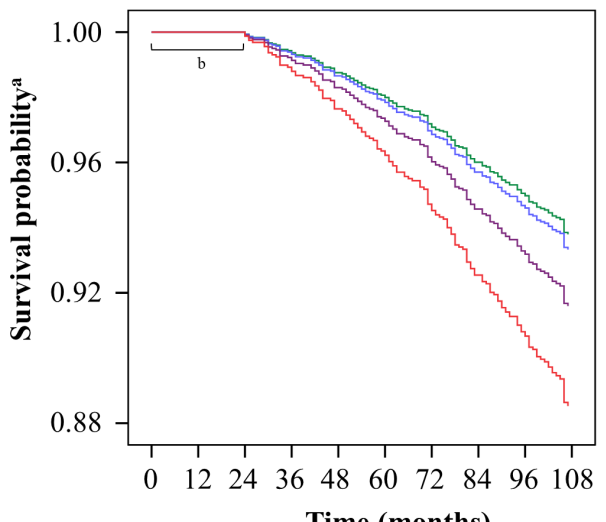

Time (months)

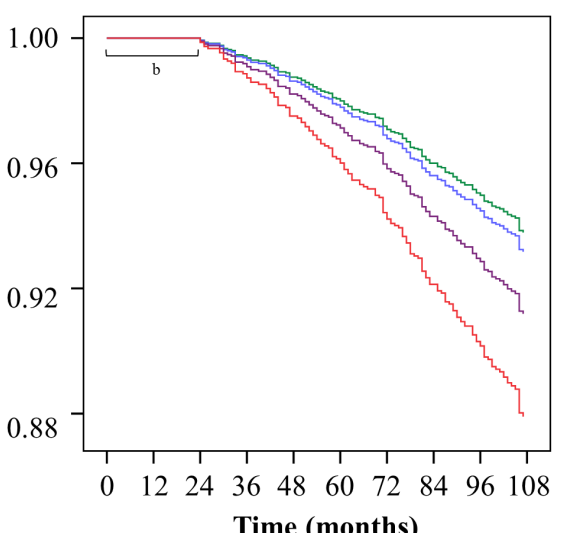

Time (months)

Figure 2 Survival probability for the different groups of adiposity and allometric power throughout the 9 year follow-up. ${ }^{\mathrm{a} A d j u s t e d ~ f o r ~ a g e, ~ s e x, ~}$ hypertension, smoking and walking and sitting times. ${ }^{b}$ Deaths within the first 24 months were excluded to minimise bias from reverse causation. 
A

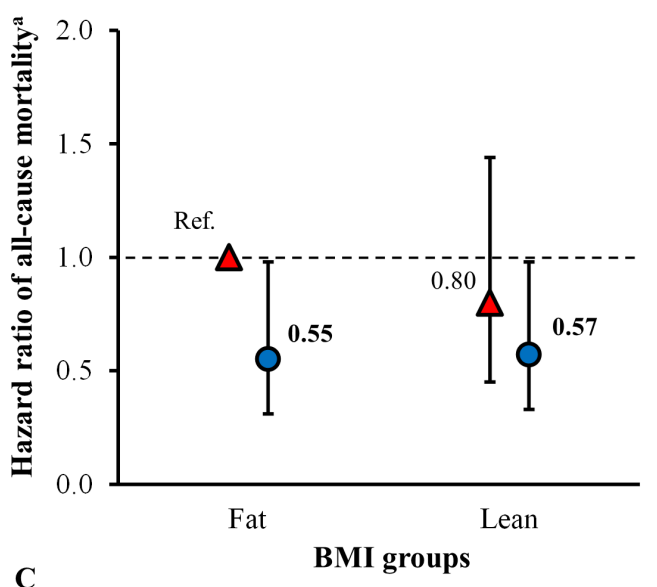

C

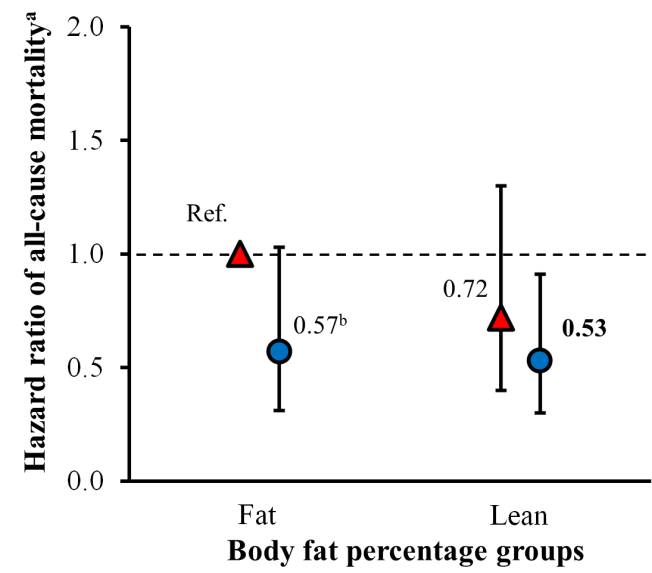

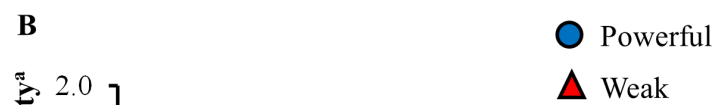

$2.07 \quad \Delta$ Weak
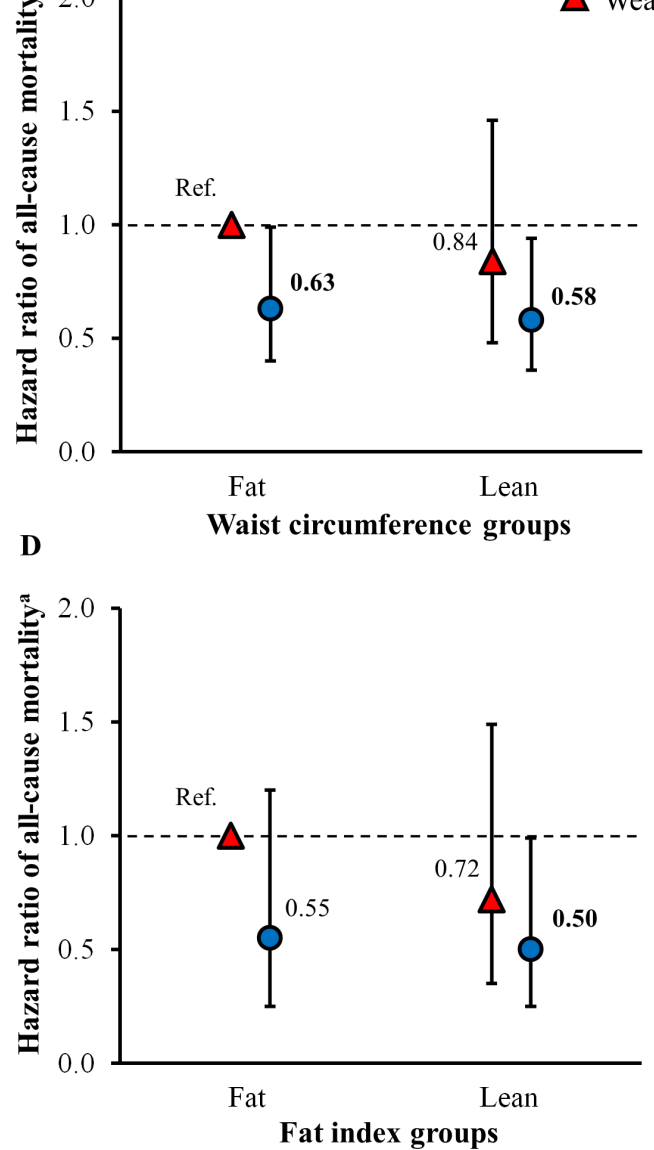

Figure 3 Hazard ratios with 95\% Cls of all-cause mortality among the different groups of allometric muscle power (powerful, blue circles, vs weak, red triangles) and adiposity (fat vs lean) according to BMI (A), waist circumference (B), body fat percentage (C) and fat index (D). BMI, body mass index. Bold values denote statistically significant differences $(p<0.05)$ compared with the reference category (fat and weak). ${ }^{a} \mathrm{Adjusted}$ for age, sex, hypertension, smoking, and walking and sitting times. ${ }^{b} p=0.060$.

in $\mathrm{F}+\mathrm{P}$ (HR (95\% CI) $0.63(0.40$ to 0.99$) ; \mathrm{p}=0.049)$ and $\mathrm{L}+\mathrm{P}$ (HR (95\% CI) 0.58 (0.36 to 0.94); $\mathrm{p}=0.025)$ participants compared with the reference group, while no significant reduction was found in the $\mathrm{L}+\mathrm{W}$ group (HR $(95 \% \mathrm{CI}) 0.84$ (0.48 to 1.46); $\mathrm{p}=0.539$ ) (figure 3B).

In terms of allometric power and body fat percentage, HRs were again significantly lower in the $\mathrm{L}+\mathrm{P}$ group $(\mathrm{HR}(95 \% \mathrm{CI})$ $0.53(0.30$ to 0.91$) ; p=0.021)$, while a trend for a reduction was noted in the $\mathrm{F}+\mathrm{P}$ participants $(\mathrm{HR}(95 \% \mathrm{CI}) 0.57$ (0.31 to $1.02) ; p=0.060)$ in comparison to the $F+W$ group. All-cause mortality risk was not significantly different in the $\mathrm{L}+\mathrm{W}$ group (HR (95\% CI) 0.72 (0.40 to 1.31$) ; \mathrm{p}=0.721)$ when compared with the reference group (figure $3 \mathrm{C}$ ).

Among the groups of allometric power and fat index, the $\mathrm{L}+\mathrm{P}$ group was the only group showing a significantly reduced allcause mortality risk when compared with the $\mathrm{F}+\mathrm{W}$ participants (HR (95\% CI) 0.50 (0.25 to 0.99); $\mathrm{p}=0.049)$, and, thus, nonsignificant reductions were noted in the $\mathrm{F}+\mathrm{P}(\mathrm{HR}(95 \% \mathrm{CI}) 0.55$ (0.25 to 1.20$) ; \mathrm{p}=0.133)$ and $\mathrm{L}+\mathrm{W}(\mathrm{HR}(95 \% \mathrm{CI}) 0.72$ (0.35 to $1.49) ; \mathrm{p}=0.370$ ) groups (figure $3 \mathrm{D}$ ).

Influence of relative muscle power on all-cause mortality Finally, when introduced as a continuous variable, higher relative muscle power significantly reduced mortality risk among the older adults independently of age, sex, hypertension, smoking and walking and sitting times (HR $(95 \% \mathrm{CI}) 0.78$ (0.63 to 0.97$)$; $\mathrm{p}=0.025)$. In addition, a significantly reduced HR of all-cause mortality was noted in the participants with normal relative muscle power (HR $(95 \% \mathrm{CI}) 0.60(0.42$ to 0.86$) ; \mathrm{p}=0.006)$ and high relative muscle power ( $\mathrm{HR}(95 \% \mathrm{CI}) 0.52$ (0.32 to 0.86 ); $\mathrm{p}=0.011)$ when compared with those with low relative muscle power (figure 4).

\section{DISCUSSION}

The main findings of the present investigation were that the $\mathrm{L}+\mathrm{P}$ older adults presented a significantly diminished all-cause mortality risk, while the $\mathrm{F}+\mathrm{P}$ participants showed a significantly reduced all-cause mortality risk only when BMI and waist circumference were considered (all independently of age, sex, hypertension, smoking status and walking and sitting times). Moreover, normal and high levels of relative muscle power, which require appropriate combinations of allometric power and BMI, independently decreased all-cause mortality in older people.

\section{Muscle power and all-cause mortality}

Traditionally, cardiorespiratory fitness has been considered the cornerstone of physical fitness. ${ }^{3}$ In recent decades, muscle strength and resistance training have gained increased attention 

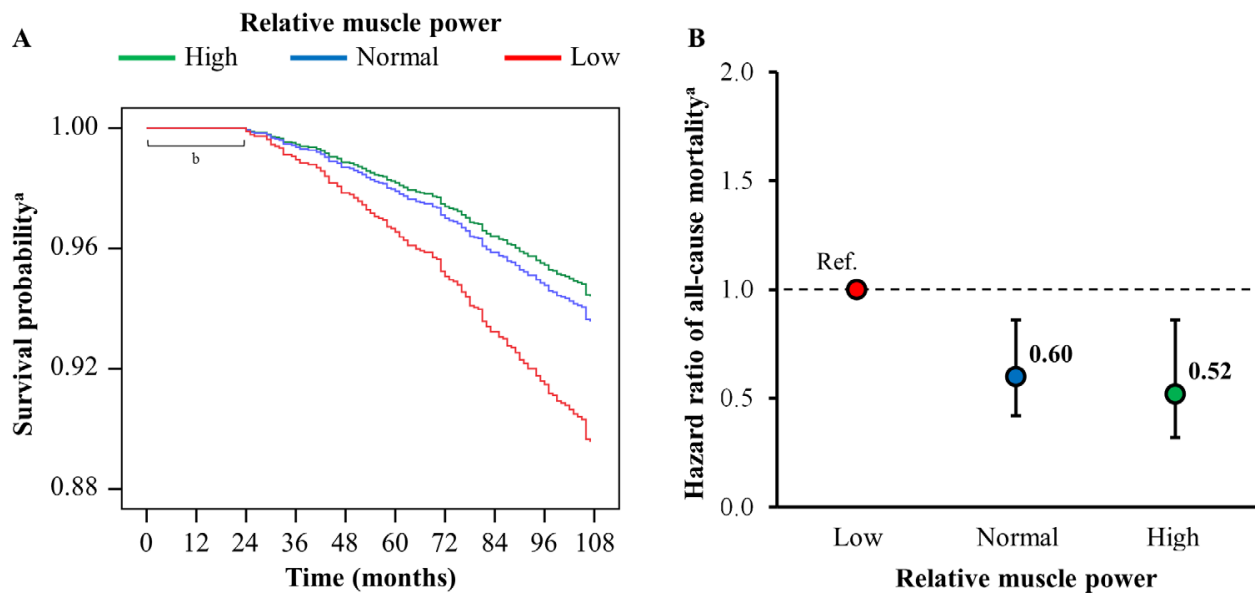

Figure 4 Survival probability (A) and hazard ratios with 95\% Cls of all-cause mortality (B) for the different groups of relative muscle power throughout the 9 year follow-up. Bold values denote statistically significant differences $(p<0.05)$ compared with the reference category (low relative power). ${ }^{a}$ Adjusted for age, sex, hypertension, smoking and walking and sitting times. ${ }^{b}$ Deaths within the first 24 months were excluded to minimise bias from reverse causation.

as numerous studies have reported their overall benefits, ${ }^{20} 21$ especially in older and clinical populations. ${ }^{22-25}$ For example, handgrip strength was demonstrated to be the third strongest modifiable risk factor for mortality when considered together with other behavioural, metabolic, socioeconomic and psychosocial factors, household and ambient pollution. ${ }^{26}$ Notably, it was found out that muscle power is a stronger predictor of functional ability in older people than muscle strength, muscle mass and aerobic capacity. ${ }^{6} 2728$ Specifically, power values obtained from the STS muscle power test have been reported to be more clinically relevant than handgrip strength and sarcopenia in older people. ${ }^{152930} \mathrm{In}$ addition, Metter et $\mathrm{al}^{7}$ demonstrated a significant association between low upper limb absolute muscle power and mortality in middle-aged men after a 25 -year follow-up, independently of muscle mass, strength and physical activity. However, due to (1) absolute muscle power is positively correlated with height and (ii) height progressively decreases across generations, the association between absolute muscle power and mortality may be-at least-partially explained by this aspect. Thus, we assessed allometric power (absolute power normalised to height squared) and confirmed the independent association of low muscle power with all-cause mortality in older men and women.

\section{The 'fat but fit/powerful' paradox}

Of note, in the current study being powerful seemed to be an independent requisite to live longer, while being lean was not. Previous studies have reported that body composition and physical fitness do not have equivalent influence on all-cause mortality risk. Ortega et $a l^{3}$ reported that being fit according to cardiorespiratory capacity decreased mortality risk in both men and women independently of the level of BMI, body fat percentage or waist circumference, while unfit individuals presented an increased mortality risk whether they were obese or not. Muscle function was also responsible for a greater proportion of deaths than abdominal obesity, hypertension, diabetes and high blood cholesterol. ${ }^{26}$ The superiority of physical fitness over body composition regarding all-cause mortality risk was especially evident among older adults. Sui et $a l^{5}$ found that allcause mortality risk was strongly modulated by cardiorespiratory fitness, while being obese or nonobese had no apparent effect on either fit or unfit older individuals. Similarly, we noted that the lean participants only presented a significantly decreased mortality risk when they were powerful as well, while all-cause mortality risk was generally significantly reduced in the powerful participants whether they were obese or not. This aspect should be considered when studying the so-called obesity paradox in older adults, ${ }^{31}$ since muscle function may act as a confounding factor and contribute, at least partially, to the observations about the benefits of having a greater BMI on the severity of certain cardiovascular conditions. ${ }^{32}$

However, in contrast to other adiposity measures, the obese group according to fat index values did not benefit significantly from being powerful. Of note, BMI and waist circumference are used as proxies of fat mass or obesity, while body fat percentage also depends on other tissues (eg, body fat percentage is reduced by increasing muscle mass). Therefore, fat index is the adiposity marker that better and more independently reflects the amount of fat mass an individual has, which may explain the observed discrepancies among the adiposity measures. The harmful effects of obesity have been directly related to an excessive accumulation of fat mass, leading to the infiltration of adipocytes within other tissues, increased systemic low-grade inflammation, loss of function and augmented mortality. ${ }^{33-35}$ Thus, an excessive accumulation of fat mass (ie, high fat index) would counteract the benefits of having adequate power levels. Nonetheless, all-cause mortality was lower (although non-significantly) in the $\mathrm{F}+\mathrm{P}$ than in the $\mathrm{L}+\mathrm{W}$ participants; thus, whether the $\mathrm{F}+\mathrm{P}$ participants according to fat index may still experience clinical benefits deserves to be further investigated. Furthermore, among the adiposity indexes, the highest survival benefit when compared with the $\mathrm{F}+\mathrm{W}$ group was observed in $\mathrm{L}+\mathrm{P}$ individuals according to fat index.

\section{Relationship between relative muscle power and all-cause mortality}

On the other hand, we also assessed the influence of relative muscle power on all-cause mortality among older people. Actually, relative muscle power combines a measure of physical fitness (allometric power) and a measure of adiposity (BMI) and is a more functionally relevant outcome compared with absolute or allometric muscle power. ${ }^{36}{ }^{37}$ In this sense, we observed normal and high levels of relative muscle power to protect against 9-year 
all-cause mortality independently of age, sex, hypertension, smoking, physical activity and sedentary time. Particularly, the survival benefits of relative muscle power seemed to plateau, and the protection conferred by high relative muscle power was relatively similar to that observed in the individuals with normal levels. The latter suggests that the relationship between relative muscle power and mortality is curvilinear. These findings help explain why the $\mathrm{L}+\mathrm{P}$ individuals generally did not exhibit a greater survival benefit than the fat and powerful participants. Relative muscle power increased progressively across the $\mathrm{F}+\mathrm{W}$, $\mathrm{L}+\mathrm{W}, \mathrm{F}+\mathrm{P}$ and $\mathrm{L}+\mathrm{P}$ groups (weighted mean $\pm \mathrm{SD}=1.75 \pm 0.40$ $\mathrm{W} / \mathrm{kg}, 2.16 \pm 0.46 \mathrm{~W} / \mathrm{kg}, 2.90 \pm 0.58 \mathrm{~W} / \mathrm{kg}$ and $3.25 \pm 0.61 \mathrm{~W} /$ $\mathrm{kg}$, respectively). Therefore, above a certain level of relative muscle power, no further survival benefits were noted. This curvilinear relationship has also been reported for the relationship between relative muscle power and physical performance in older adults. ${ }^{3638}$

\section{Limitations}

Among the main limitations of the study, there was a relatively moderate-to-high type II error probability for the comparisons between the $\mathrm{F}+\mathrm{W}$ and $\mathrm{L}+\mathrm{W}$ groups (ie, $\beta>0.2$ ). In this sense, future analyses comprising longer follow-up periods and larger number of events may denote a significant benefit derived from being $\mathrm{L}+\mathrm{W}$ compared with $\mathrm{F}+\mathrm{W}$. However, this issue does not limit the conclusions reported regarding the survival benefits of being powerful regardless of obesity. It should be noted that the present investigation focused on independently living and noninstitutionalised older adults, so our results may not apply to other older populations. On the contrary, the representativeness of our sample makes our results applicable to the general population of noninstitutionalised Spanish older adults. In addition, a comprehensive assessment and recording of medical conditions and previous smoking was not performed, which could have improved our cox regression models. In this line, the consideration of other potential confounding variables may be of relevance for future studies. However, we did consider the main medical conditions and risk factors that have been related to allcause mortality (hypertension, smoking, physical inactivity and obesity). ${ }^{16}$ On the other hand, interventions assessing the impact of improving or worsening muscle power on all-cause mortality need to be conducted to establish a causal relationship. There is evidence showing that participation in strength training provides survival benefits, ${ }^{23}$ but whether this aspect is related to induced muscle power adaptations remains to be investigated. Finally, the procedure used in the present study to assess muscle power augments the applicability of our results, given that the STS muscle power test ${ }^{8939}$ is a valid, feasible and rapid test that can be performed in almost any global context, as long as a chair and a stopwatch are available. Further studies should be conducted to assess the influence of the 'fat but fit (powerful)' paradox on the incidence of specific medical conditions and hospitalisation.

\section{CONCLUSIONS}

Older people with adequate levels of muscle power exhibited a reduction in 9-year all-cause mortality whether they were obese or not (according to BMI, waist circumference or body fat percentage), while being lean was a survival factor only when accompanied by adequate levels of muscle power. However, when fat index was regarded, reduced all-cause mortality risk was only observed in $\mathrm{L}+\mathrm{P}$ older adults, and so the survival benefits derived from being powerful were counteracted by the obese condition. Therefore, the 'fat but fit/powerful' paradox should be revisited using fat index as the adiposity marker. Finally, low relative muscle power assessed with the STS muscle power test was an independent risk factor for 9-year all-cause mortality in a representative sample of noninstitutionalised Spanish older people.

\section{Key messages}

What are the findings?

- Older men and women with adequate levels of muscle power showed a 9-year survival benefit compared with their counterparts with low levels of muscle power, regardless of body mass index, waist circumference and body fat percentage levels.

- Obesity according to fat index (ie, body fat normalised to height squared) mitigated the survival benefits provided by adequate levels of muscle power in older adults.

- The 'fat but fit/powerful' paradox was confirmed when adiposity was assessed by BMI, waist circumference and body fat percentage, but not by fat index.

- Low relative muscle power (ie, power normalised to body mass) was an independent predictor of 9-year all-cause mortality among older people.

How might it impact on clinical practice in the future?

- If possible, the assessment of fat index should be preferred over other adiposity markers since it is more appropriate for quantifying the amount of body fat and was the only obesity marker that mitigated the survival benefits of muscle power.

- Nevertheless, in the fatness and fitness binomial, the greatest importance should be granted to the physical fitness component in terms of preventing mortality among older people.

- The assessment of low relative muscle power should be strongly encouraged in daily clinical practice given the previous evidence showing its detrimental consequences on physical performance and the novel evidence demonstrating its harmful effect on all-cause mortality among older people.

\section{Author affiliations}

'GENUD Toledo Research Group, Universidad de Castilla-La Mancha, Toledo, Spain

${ }^{2} \mathrm{CIBER}$ of Frailty and Healthy Aging (CIBERFES), Madrid, Spain

${ }^{3}$ GENUD Research Group, University of Zaragoza, Zaragoza, Spain

${ }^{4}$ Faculty of Health Sciences, Department of Physiatry and Nursing, University of Zaragoza, Zaragoza, Spain

${ }^{5}$ Centro Universitario de la Defensa, Zaragoza, Spain

${ }^{6}$ Centro de Investigación Biomédica en Red de Fisiopatología de la Obesidad y Nutrición (CIBEROBN), Madrid, Spain

${ }^{7}$ ImFine Research Group, Department of Health and Human Performance, Universidad Politécnica de Madrid, Madrid, Spain

${ }^{8}$ Institute of Biomedicine (IBIOMED), University of León, León, Spain

${ }^{9}$ International Institute for Aging, Cáceres, Spain

${ }^{10}$ Physical Activity and Quality of Life Research Group (AFYCAV), Faculty of Sport Sciences, University of Extremadura, Cáceres, Spain

${ }^{11}$ Faculty of Health and Sport Sciences, Department of Physiatry and Nursing, University of Zaragoza, Huesca, Spain

\section{Twitter Julian Alcazar @JulianAlcazr and Luis M Alegre @luismalegre}

Contributors All authors were involved in data collection, analysis, writing and revision of the manuscript, and approved the final version submitted.

Funding This work was supported by the Universidad de Zaragoza (UZ 2008 BIO-01); Gobierno de Aragón (Grant DGAIIU/1/20 to D.N.); Ministerio de Sanidad, Servicios Sociales e Igualdad (147/2011); Ministerio de Trabajo y Asuntos Sociales Sociales-IMSERSO (104/07); Centro Universitario de la Defensa de Zaragoza (UZCUD2016-BI0-01); Ministerio de Economía, Industria y Competitividad (DEP2016-78309-R); and the Biomedical Research Networking Center on Frailty and Healthy Aging (CIBERFES) and FEDER funds from the European Union (Grant CB16/10/00477). All the authors are members of EXERNET (https://redexernet.com/) which supported this research by funding of the Ministerio de Educación y Ciencia 
(Red EXERNET DEP2005-00046) and Consejo Superior de Deportes (09/UPB/19 and 45/UPB/20).

Competing interests None declared.

Patient and public involvement Patients and/or the public were not involved in the design, or conduct, or reporting, or dissemination plans of this research.

Patient consent for publication Not required.

Ethics approval The study was approved by the Clinical Research Ethics Committee of Aragón (18/2008) and the Ethical Committee of the University Hospital Fundación Alcorcón (50/2016).

Provenance and peer review Not commissioned; externally peer reviewed.

Data availability statement The data that support the findings of this study are available from the corresponding author on reasonable request.

\section{ORCID iDs}

Julian Alcazar http://orcid.org/0000-0002-1090-5482

Jose Antonio Casajús http://orcid.org/0000-0002-7215-6931

Ignacio Ara http://orcid.org/0000-0002-2854-6684

\section{REFERENCES}

1 Blair SN. Physical inactivity: the biggest public health problem of the 21st century. $\mathrm{Br}$ J Sports Med 2009;43:1-2

2 Mandsager K, Harb S, Cremer P, et al. Association of cardiorespiratory fitness with long-term mortality among adults undergoing exercise treadmill testing. JAMA Netw Open 2018;1:e183605.

3 Ortega FB, Lavie CJ, Blair SN. Obesity and cardiovascular disease. Circ Res 2016;118:1752-70.

4 Ortega FB, Ruiz JR, Labayen I, et al. The Fat but Fit paradox: what we know and don't know about it. Br J Sports Med 2018;52:151-3.

5 Sui X, LaMonte MJ, Laditka JN, et al. Cardiorespiratory fitness and adiposity as mortality predictors in older adults. JAMA 2007;298:2507-16.

6 Foldvari M, Clark M, Laviolette LC, et al. Association of muscle power with functional status in community-dwelling elderly women. J Gerontol A Biol Sci Med Sci 2000:55:M192-9.

7 Metter EJ, Talbot LA, Schrager M, et al. Arm-cranking muscle power and arm isometric muscle strength are independent predictors of all-cause mortality in men. J Appl Physiol 2004;96:814-21.

8 Alcazar J, Losa-Reyna J, Rodriguez-Lopez C, et al. The sit-to-stand muscle power test: an easy, inexpensive and portable procedure to assess muscle power in older people. Exp Gerontol 2018;112:38-43.

9 Alcazar J, Kamper RS, Aagaard P, et al. Relation between leg extension power and 30 $\mathrm{s}$ sit-to-stand muscle power in older adults: validation and translation to functional performance. Sci Rep 2020;10:16337.

10 Gomez-Cabello A, Pedrero-Chamizo R, Olivares PR, et al. Prevalence of overweight and obesity in non-institutionalized people aged 65 or over from Spain: the elderly EXERNET multi-centre study. Obes Rev 2011;12:583-92.

11 Pedrero-Chamizo R, Gómez-Cabello A, Delgado S, et al. Physical fitness levels among independent non-institutionalized Spanish elderly: the elderly EXERNET multi-center study. Arch Gerontol Geriatr 2012;55:406-16.

12 WHO. Physical status: the use and interpretation of anthropometry. Report of a WHO expert committee; 1995.

13 Lean ME, Han TS, Morrison CE. Waist circumference as a measure for indicating need for weight management. BMJ 1995;311:158-61.

14 Gallagher D, Heymsfield SB, Heo M, et al. Healthy percentage body fat ranges: an approach for developing guidelines based on body mass index. Am J Clin Nutr 2000;72:694-701.

15 Losa-Reyna J, Alcazar J, Rodríguez-Gómez I, et al. Low relative mechanical power in older adults: an operational definition and algorithm for its application in the clinical setting. Exp Gerontol 2020;142:111141.

16 WHO. Global health risks: mortality and burden of disease attributable to selected major risks; 2009.
17 López-Rodríguez C, Laguna M, Gómez-Cabello A, et al. Validation of the self-report EXERNET questionnaire for measuring physical activity and sedentary behavior in elderly. Arch Gerontol Geriatr 2017;69:156-61.

18 Ekelund U, Tarp J, Steene-Johannessen J, et al. Dose-Response associations between accelerometry measured physical activity and sedentary time and all cause mortality: systematic review and harmonised meta-analysis. BMJ 2019:366:14570.

19 Schoenfeld DA. Sample-size formula for the proportional-hazards regression model. Biometrics 1983:39:499-503.

20 Metter EJ, Talbot LA, Schrager M, et al. Skeletal muscle strength as a predictor of all-cause mortality in healthy men. J Gerontol A Biol Sci Med Sci 2002;57:B359-65.

21 Feigenbaum MS, Pollock ML. Prescription of resistance training for health and disease. Med Sci Sports Exerc 1999;31:38-45.

22 Guadalupe-Grau A, Carnicero JA, Gómez-Cabello A, et al. Association of regional muscle strength with mortality and hospitalisation in older people. Age Ageing 2015:44:790-5.

23 Kraschnewski JL, Sciamanna CN, Poger JM, et al. Is strength training associated with mortality benefits? A 15year cohort study of US older adults. Prev Med 2016;87:121-7.

24 Hairi NN, Cumming RG, Naganathan V, et al. Loss of muscle strength, mass (sarcopenia), and quality (specific force) and its relationship with functional limitation and physical disability: the Concord health and ageing in men project. J Am Geriatr Soc 2010;58:2055-62.

25 Carbone S, Kirkman DL, Garten RS, et al. Muscular strength and cardiovascular disease: an updated state-of-the-art narrative review. J Cardiopulm Rehabil Prev 2020;40:302-9.

26 Yusuf S, Joseph P, Rangarajan S, et al. Modifiable risk factors, cardiovascular disease, and mortality in 155722 individuals from 21 high-income, middle-income, and lowincome countries (PURE): a prospective cohort study. Lancet 2020;395:795-808.

27 Bean JF, Leveille SG, Kiely DK, et al. A comparison of leg power and leg strength within the InCHIANTI study: which influences mobility more? I Gerontol A Biol Sc Med Sci 2003;58:M728-33.

28 Lauretani F, Russo CR, Bandinelli S, et al. Age-Associated changes in skeletal muscles and their effect on mobility: an operational diagnosis of sarcopenia. J Appl Physiol 2003;95:1851-60

29 Alcazar J, Kamper RS, Aagaard P, et al. Relation between leg extension power and 30$\mathrm{S}$ sit-to-stand muscle power in older adults: validation and translation to functional performance. Sci Rep 2020;10:16337.

30 Bahat G, Kilic C, Eris S, et al. Power versus sarcopenia: associations with functionality and physical performance measures. J Nutr Health Aging 2021;25:13-17.

31 Wang S, Ren J. Obesity paradox in aging: from prevalence to pathophysiology. Prog Cardiovasc Dis 2018:61:182-9.

32 Elagizi A, Kachur S, Lavie CJ, et al. An overview and update on obesity and the obesity paradox in cardiovascular diseases. Prog Cardiovasc Dis 2018:61:142-50.

33 Visser M, Kritchevsky SB, Goodpaster BH, et al. Leg muscle mass and composition in relation to lower extremity performance in men and women aged 70 to 79 : the health, aging and body composition study. J Am Geriatr Soc 2002;50:897-904

34 Ortega FJ, Fernández-Real JM. Inflammation in adipose tissue and fatty acid anabolism: when enough is enough! Horm Metab Res 2013;45:1009-19.

35 Alley DE, Crimmins E, Bandeen-Roche K, et al. Three-Year change in inflammatory markers in elderly people and mortality: the Invecchiare in Chianti study. J Am Geriatr Soc 2007; 55:1801-7.

36 Alcazar J, Rodriguez-Lopez C, Ara I, et al. The force-velocity relationship in older people: reliability and validity of a systematic procedure. Int I Sports Med 2017:38:1097-104.

37 Alcazar J, Rodriguez-Lopez C, Ara I, et al. Force-Velocity profiling in older adults: an adequate tool for the management of functional trajectories with aging. Exp Gerontol 2018;108:1-6

38 Bean JF, Kiely DK, Herman S, et al. The relationship between leg power and physical performance in mobility-limited older people. J Am Geriatr Soc 2002:50:461-7.

39 Baltasar-Fernandez I, Alcazar J, Rodriguez-Lopez C, et al. Sit-to-stand muscle power test: comparison between estimated and force plate-derived mechanical power and their association with physical function in older adults. Exp Gerontol 2021:145:111213. 